\title{
The potential of video games as a pedagogical tool
}

\author{
Brandon K. Ashinoff* \\ School of Psychology, University of Birmingham, Birmingham, UK \\ *Correspondence: brandon.ashinoff@gmail.com \\ Edited by: \\ Clare Wood, Coventry University, UK \\ Reviewed by: \\ Kevin Durkin, University of Strathclyde, UK
}

Keywords: video games, educational technology, cognitive training, plasticity and learning, games for learning, training-induced changes, training effects

When I was seven years old, my parents bought me and my brother a Nintendo Entertainment System, which they would eventually refer to as "The Idiot Box." There was an implicit assumption (one that persists in much of the general public today) that video games were simply a toy and nothing of real substance could be gained from them. Considering this, and the prevalence of video games in society (59\% of Americans play video games; Entertainment Software Association, 2014), numerous questions have been raised about the long term effects of regular use. While the media focus is generally on potential negative effects (see Ferguson and Kilburn, 2009, 2010; Anderson et al., 2010; Bushman et al., 2010; Rowell, 2010 for debate on violent video games causing aggression in gamers), there is also evidence to suggest that there may be a range of potential positive effects of video games. It should be noted that when "video games" are referenced in this article it is specifically with regard to commercial, "for fun" games and not games that were designed with educational purposes or cognitive training in mind. This article argues that video games can be a useful pedagogical tool for educators at all levels of academia.

Let's consider a simple anecdotal example of how video games may encourage children to learn large amounts of information. Pokémon is a popular children's game in which the player has to fight and collect various creatures, called "Pokémon." In the original Pokémon game, there were 150 Pokémon that could be found. Each Pokémon has a name, a "type" (like water type or fire type), a weakness and a strength (fire types are weak against water types, but strong against grass types), and a stage of its evolution (some Pokémon can turn into a new one if you used it enough). Roughly speaking, this gives us 5 distinct pieces of information per Pokémon and multiplying this by 150 gives 750 distinct units of information contained by the list of all the Pokémon in the first Pokémon game. Now let's consider another list of information that is considered more educationally important: the periodic table of the elements. Within the periodic table each element is defined by a symbol, a name, an atomic number and weight, a phase at room temperature, and its metal or gas type. That comes to 6 distinct units of information per cell. Multiplying this by 118 , the total number of elements, returns 708 distinct units of information in the periodic table. What makes this interesting is that there are a large numbers of young children (and adults for that matter) who can recite, from memory much of the information contained in this list of Pokémon, but it would likely be difficult to find the same number of people who could do that for the periodic table. The point is that the medium of video games appears to have the potential facilitate significant learning.

As it turns out, video games are designed to effectively be learning machines (Gee, 2003, 2005). If fact, many games start off with a simple tutorial level that teaches the player the basic mechanics of the game. Throughout the game, the strategy, and tactics needed to complete tasks become more complex while the teaching method gradually switches from an explicit tutorial to an experience based process. Essentially, games teach the player the skills needed to critically evaluate any situation within the game and determine the best course of action. Starcraft 2 (as well as its predecessors Starcraft and Starcraft: Brood War) is what is called a "Real Time Strategy" game. Players must obtain various resources and use them to purchase buildings and fighting units. Then, they must fight and defeat their enemy. To play this game successfully, players must manage their time and resources more efficiently than their opponents as each building and unit have a different cost, purpose, and build time. Additionally, much like Pokémon, units have strengths and weakness. A player has to constantly update their strategies throughout the game based on their interactions with the other players, requiring significant planning and critical thinking skills that are honed by players over time. In fact, while Starcraft beginners make less than 100 actions (or decisions) per minute, professionals can make over 400 per minute (Lewis et al., 2011; Latham et al., 2013).

Despite evident in-game learning, one concern is that video games can only be used to teach players about gamerelated information and not about educationally relevant material. However, recent research into the field of digital game based learning (Prensky, 2003, 2005; Pivec, 2007; Hwang and $\mathrm{Wu}, 2012$; also see Young et al., 2012) suggests that this is not the case. Squire (2005) conducted a qualitative case study on a secondary school history class in which he had students play an historical simulation game called Civilization 3 with the intention of having the students learn about history from playing the game. It should be noted that this game was not designed specifically as an educational game (see Girard et al. (2013) for a review of the effect of intentionally educational games). In this game, students take control 
of a civilization (like the Aztecs or the French, for example) and progress through history developing technology, engaging in simulated warfare and diplomacy, and managing the economies of their empires. Squire (2005) reported that playing this game for educational purposes seemed to benefit students who struggled with traditional education, though students who typically performed well preferred traditional teaching methods. Here is a brief excerpt of an interview with one of the students in this study:

\begin{abstract}
"Interviewer: Who do you think invented the alphabet before you played this game?

Marvin: The English, because back then they were the classiest and smartest.

Interviewer: Now who do you think invented the alphabet?

Marvin: Probably the Egyptians with the hieroglyphics. It was the first writing to be done." (Squire, 2005)
\end{abstract}

When you play Civilization 3, you have to develop technology based on a set path. For example, you are required to invent the alphabet before you invent other things, like formal mathematics. Therefore, it is possible for this simple video game mechanic to teach players that the alphabet had to be invented in the first place and that it was invented before other things. Therefore, developing science in the game gives students a better idea of when things occurred in history.

Another way in which video games are learning machines (Gee, 2003, 2005) is that they are highly motivating and therefore they can induce higher student engagement compared to traditional teaching methods. According to Hamlen (2013), "despite assumptions that children play video games to avoid mental stimulation, children are actually motivated by the challenge and thinking required by video games." Squire (2005) reported that Marvin voluntarily, and without provocation, spent time learning more about history from the "civelopedia" which provides players with historically accurate information about their chosen civilizations and other aspects of the game. Improved student engagement using video games was also demonstrated by Stansbury and Munro (2013; Stansbury et al., 2014) who supplemented an undergraduatelevel behavioral statistics lecture by having students play the game Dance Dance Revolution $(D D R)$ to generate scores that would be used as dependent variables while teaching the students about factorial research designs. They found, based on a pre-test/post-test comparison, that students who played $D D R$ as part of their lecture showed a greater increase in content knowledge compared to students who received a traditional lecture on the same topic. Even through the inherent content of $D D R$ was not educationally relevant, clever pedagogical use of the game had the desired effect of increasing student engagement with the lecture content.

\section{LEARNING TO LEARN}

There are also potential positive effects of video games that could have a less direct influence on learning and education. Harlow (1949; also see Green and Bavelier, 2008) coined the term "learning to learn," which refers to "the process of developing skills that facilitate learning in other contexts..." (Bisoglio et al., 2014). Critically, there is evidence that video game training can influence numerous skills and abilities that are crucial to the learning process. For example, Kühn et al. (2014) trained 48 non-video game players $\left(M_{\text {Age }}=24.1 ; S_{\text {Age }}=3.8\right)$ on Super Mario 64 for $30 \mathrm{~min}$ a day for 2 months. Super Mario 64 is a game in which the player must explore the game world, fight monsters, solve puzzles, and collect stars to progress. Gray matter volume was measured pre- and post- training and it was found that the volume of gray matter in the right dorsolateral pre-frontal cortex was significantly increased posttraining. There is evidence to suggest that an increase in cortical volume due to video game training is related to improvements in the concomitant cognitive functions of that brain region (Basak et al., 2011; Voss et al., 2012). The dorsolateral pre-frontal cortex is has been frequently implicated in executive functions-including working memory (Goldman-Rakic, 1995; Bechara et al., 1998; Levy and GoldmanRakic, 2000; Petrides, 2000; Curtis and D'Esposito, 2003), inhibitory control (Knight et al., 1999; MacDonald et al., 2000; Ridderinkhof et al., 2004), and attentional shifting (Nagahama et al.,
2001; Kondo et al., 2004)_all of which are arguably critical to the learning process in an educational setting. There is also a wealth of behavioral evidence that video game training influences cognitive abilities including executive function (Maclin et al., 2011; Mathewson et al., 2012; Strobach et al., 2012; Anguera et al., 2013), spatial attention (Green and Bavelier, 2003, 2006a,b, 2007; Feng et al., 2007; Dye et al., 2009; HubertWallander et al., 2011), selective attention (Wu et al., 2012; Belchior et al., 2013; Wu and Spence, 2013), distractor processing (Mishra et al., 2011; Krishnan et al., 2013), and attentional capture (West et al., 2008; Chisholm et al., 2010). There is even evidence to suggest that video gamers generate more robust internal representations of visual information (Green and Bavelier, 2004; Karle and James, 2011; Sungur and Boduroglu, 2012). However, a caveat is that due to inconsistent methodologies across the research in the field there is still debate over whether or not there is a causal relationship between playing video games and improved cognition (Boot et al., 2008, 2011, 2013; Boot and Simons, 2012; Schubert and Strobach, 2012; Kristjánsson, 2013; Latham et al., 2013; Bisoglio et al., 2014). That being said, overall the evidence appears to be trending toward there being a causal relationship.

In addition to the cognitive skills necessary for learning, appropriate social skills are necessary for success in education because education in general is a highly social experience. It should be noted that although cognitive and social skills are being separated in this article for the sake of clarity, they are deeply interrelated abilities in practice. Being a student (or a teacher for that matter) requires constant interaction and communication with other people. This interaction can take the form of a lecture, group assignments, study groups, or even general emotional and social support. An often overlooked aspect of video games is that they too can be a highly social experience. Despite this, a common misconception about video gamers is that they shun and avoid social engagement (Jenkins, 2005). Consider that many modern video games are multiplayer online games. For example, World of Warcraft is what is known as a massively multiplayer online role playing game 
(MMORPG). In this game, to defeat enemies and to progress through the game, players must interact and coordinate with each other. In some cases the execution of a sophisticated strategy, involving up to 40 players, is required to win a battle. It has been suggested that MMORPG's can provide a medium through which one can learn and practice social skills (Ducheneaut and Moore, 2004, 2005; Yee, 2006; Zhong, 2011). Jang and Ryu (2011) analyzed survey data from 300 Korean MMORPG players $\left(M_{\text {Age }}=25.4 ; S_{\text {Age }}=\right.$ 5.9) about their gaming habits and their leadership experiences (both online and offline). The results revealed a positive correlational relationship between online leadership experiences and with offline leadership experiences (each measured using a different leadership questionnaire). While correlations only allow for a limited interpretation there is converging evidence to suggest that the video game play may be a causal or at least influencing factor. Yee (2003), based on a survey analysis of 2804 MMORPG players (age not reported), reported that almost half of all subjects subjectively felt that they had improved their leadership skills, defined by four subcategories, at least a little bit as a result of their gaming experiences: Mediation (55.2\%), Motivation (48.4\%), Persuasion (43.8\%), and Leadership (50.3\%). Interestingly, being in a leadership or management role in real life did not seem to affect the rate at which subjects reported improved leadership skills, suggesting playing MMORPGs could have social benefits for a wide range of people.

Additionally, competitive online team games also provide an excellent medium for enhancing social skills, particularly teamwork, and collaboration. A game mentioned earlier, Starcraft 2, has a highly in depth competitive culture and multiplayer community (as do games like League of Legends and DOTA 2). Poling (2013) conducted a study in which he taught an entire course using Starcraft 2 as the primary mode of instruction throughout. According to Poling (2013) "the StarCraft 2 course encouraged learners to create new knowledge by synthesizing what they know and learn in the game world with how they can apply those skills and concepts to their real-life professional world. It used StarCraft 2 as a digital sandbox where they had to learn to work well with others in order to succeed." Based on interviews from three participants, it was expressed that they felt they had enhanced their knowledge regarding "collaboration, teamwork, and leadership" as a result of the course. Poling (2013) reported that "one of the most important lessons they learned from both the inperson and online collaboration processes was that collaboration is essentially about managing human relationships, maintaining effective communication, and learning how to work with others despite their differences."

Video games have also been shown to be able to influence pro-social behaviors. Greitemeyer and Osswald (2010) conducted a study in which they had subjects $\left(M_{\text {Age }}=21.81 ; S_{\text {Age }}=\right.$ not reported; university students) play one of four games. In the interest of brevity, I will focus on only two. One of those games was called Lemmings and was chosen because they researchers deemed it a pro-social game. In this game, Lemmings drop from an entrance and walk forward unless there is something in their path, in which case they turn around. If the player does nothing, they will walk off the edge of cliffs and die. The purpose of the game is to guide the lemmings safely to the exits using a limited number of skills. It was deemed pro-social because the focus of the game is helping the lemming survive. The game Tetris was used as a neutralsocial game. In this game, players must arrange geometrical shapes into horizontal lines to earn points. Players were asked to play their respective game for $8 \mathrm{~min}$. After playing, they were presented with various social situations and their responses were recorded. The subjects were unaware that these were part of the study. In one study, the experimenter knocked some pencils onto the floor while talking to the subject. In another (which used a different pro-social game), a male confederate entered the room and verbally and physically harassed a female experimenter as if he were an ex-boyfriend who couldn't accept that their relationship was over. In both cases, the subjects who played the pro-social game were more likely to help the experimenter than the subjects who played the neutral game. The point is video games can have a positive influence on social behaviors (Durkin and Barber, 2002; Lenhart et al., 2008; Dalisay et al., in press), at least when played in moderation (Przybylski, 2014). Prosocial video games like lemmings can foster altruism, which could be good for encouraging students to help each other if one of them is struggling in class, and multiplayer games like World of Warcraft or Starcraft 2 can foster the social skills needed to coordinate and cooperate with other people, which could enhance student's ability to engage in group assignments.

Video games have significant potential as a pedagogical tool. In order to begin to explore this potential, the common preconceptions about what video games are and their value must be re-evaluated. In general, there are two rules of thumb that one should keep in mind when considering how to use video games in an educational context. First and foremost, it matters what games you are playing. Puzzle games like Portal, may improve problem solving skills, but do nothing to improve social skills or attentional processing. Multiplayer team games like League of Legends may improve the ability to communicate and cooperate with groups, but may not affect interest in learning more about school work. Historical simulation games, like the Civilization series might enhance a student's motivation to learn more about history, but have no influence over executive functions. It is therefore important to pick and choose the games you may want to use carefully. And second, video games cannot replace a teacher or a curriculum, but judicious use of the appropriate games can complement an educational program.

\section{ACKNOWLEDGMENT}

The author would like to thank Jeanette Rose Moreland for providing thoughtful and helpful comments on early versions of this manuscript.

\section{REFERENCES}

Anderson, C. A., Shibuya, A., Ihori, N., Swing, E. L., Bushman, B. J., Sakamoto, A., et al. (2010). Violent video game effects on aggression, empathy, and prosocial behavior in Eastern and Western countries: a meta-analytic review. Psychol. Bull. 136, 151-173. doi: 10.1037/a0018251

Anguera, J. A., Boccanfuso, J., Rintoul, J. L., AlHashimi, O., Faraji, F., Janowich, J., et al. (2013). 
Video game training enhances cognitive control in older adults. Nature 501, 97-101. doi: 10.1038/nature12486

Basak, C., Voss, M. W., Erickson, K. I., Boot, W. R., and Kramer, A. F. (2011). Regional differences in brain volume predict the acquisition of skill in a complex real-time strategy videogame. Brain Cogn. 76, 407-414. doi: 10.1016/j.bandc.2011.03.017

Bechara, A., Damasio, H., Tranel, D., and Anderson, S. W. (1998). Dissociation of working memory from decision making within the human prefrontal cortex. J. Neurosci. 18, 428-437.

Belchior, P., Marsiske, M., Sisco, S. M., Yam, A., Bavelier, D., Ball, K., et al. (2013). Video game training to improve selective visual attention in older adults. Comput. Human Behav. 29, 1318-1324. doi: 10.1016/j.chb.2013.01.034

Bisoglio, J., Michaels, T. I., Mervis, J. E., and Ashinoff, B. K. (2014). Cognitive enhancement through action video game training: great expectations require greater evidence. Front. Psychol. 5:136. doi: 10.3389/fpsyg.2014.00136

Boot, W. R., Blakely, D. P., and Simons, D. J. (2011). Do action video games improve perception and cognition? Front. Psychol. 2:226. doi: 10.3389/fpsyg.2011.00226

Boot, W. R., Champion, M., Blakely, D. P., Wright, T., Souders, D. J., and Charness, N. (2013). Video games as a means to reduce age-related cognitive decline: attitudes, compliance, and effectiveness. Front. Psychol. 4:31. doi: 10.3389/fpsyg.2013.00031

Boot, W. R., Kramer, A. F., Simons, D. J., Fabiani, M., and Gratton, G. (2008). The effects of video game playing on attention, memory, and executive control. Acta Psychol. 129, 387-398. doi: 10.1016/j.actpsy.2008.09.005

Boot, W. R., and Simons, D. J. (2012). Advances in video game methods and reporting practices (but still room for improvement): a commentary on Strobach, Frensch, and Schubert (2012). Acta Psychol. 141, 276-277. doi: 10.1016/j.actpsy.2012.06.011

Bushman, B. J., Rothstein, H. R., and Anderson, C. A. (2010). Much ado about something: violent video game effects and a school of red herring: reply to Ferguson and Kilburn (2010). Psychol. Bull. 136, 182-187. doi: 10.1037/a0018718

Chisholm, J. D., Hickey, C., Theeuwes, J., and Kingstone, A. (2010). Reduced attentional capture in action video game players. Atten. Percept. Psychophys. 72, 667-671. doi: 10.3758/APP.72.3.667

Curtis, C. E., and D'Esposito, M. (2003). Persistent activity in the prefrontal cortex during working memory. Trends Cogn. Sci. 7, 415-423. doi: 10.1016/S1364-6613(03)00197-9

Dalisay, F., Kushin, M. J., Yamamoto, M., Liu, Y.-I., and Skalski, P. (in press). Motivations for game play and the social capital and civic potential of video games. New Media Soc. doi: 10.1177/1461 444814525753

Ducheneaut, N., and Moore, R. J. (2004). "Gaining more than experience points: learning social behavior in multiplayer computer games," in Conference Proceedings on Human Factors in Computing Systems (CHI2004): Extended Abstracts. Available online at: http://www2.parc.com/nicolas/documents/CHI20 04-social_learning.pdf
Ducheneaut, N., and Moore, R. J. (2005). More than just "XP": learning social skills in massively multiplayer online games. Interact. Technol. Smart Educ. 2, 89-100. doi: 10.1108/17415650580000035

Durkin, K., and Barber, B. (2002). Not so doomed: computer game play and positive adolescent development. J. Appl. Dev. Psychol. 23, 373-392. doi: 10.1016/S0193-3973(02)00124-7

Dye, M. W. G., Green, C. S., and Bavelier, D. (2009). The development of attention skills in action video game players. Neuropsychologia 47, 1780-1789. doi: 10.1016/j.neuropsychologia.2009.02.002

Entertainment Software Association. (2014). Essential facts about the computer and video game industry: sales, demographics, and usage data. Available online at: http://www.theesa.com/facts/ pdfs/esa_ef_2014.pdf

Feng, J., Spence, I., and Pratt, J. (2007). Playing an action video game reduces gender differences in spatial cognition. Psychol. Sci. 18, 850-855. doi: 10.1111/j.1467-9280.2007.01990.x

Ferguson, C. J., and Kilburn, J. (2009). The public health risks of media violence: a metaanalytic review. J. Pediatr. 154, 759-763. doi: 10.1016/j.jpeds.2008.11.033

Ferguson, C. J., and Kilburn, J. (2010). Much ado about nothing: the misestimation and overinterpretation of violent video game effects in Eastern and Western nations: comment on Anderson et al. (2010). Psychol. Bull. 136, 174-178. doi: $10.1037 / \mathrm{a} 0018566$

Gee, J. P. (2003). What video games have to teach us about learning and literacy. Comput. Entertain. 1, 20. doi: $10.1145 / 950566.950595$

Gee, J. P. (2005). Learning by design: good video games as learning machines. E-Learning 2, 5-16. doi: 10.2304/elea.2005.2.1.5

Girard, C., Ecalle, J., and Magnan, A. (2013). Serious games as new educational tools: how effective are they? A meta-analysis of recent studies. J. Comput. Assist. Learn. 29, 207-219. doi: 10.1111/j.13652729.2012.00489.x

Goldman-Rakic, P. S. (1995). Cellular basis of working memory. Neuron 14, 477-485. doi: 10.1016/08966273(95)90304-6

Green, C., and Bavelier, D. (2006a). Enumeration versus multiple object tracking: the case of action video game players. Cognition 101, 217-245. doi: 10.1016/j.cognition.2005.10.004

Green, C. S., and Bavelier, D. (2003). Action video game modifies visual selective attention. Nature 423, 534-537. doi: 10.1038/nature01647

Green, C. S., and Bavelier, D. (2004). Does action video game play really enhance the number of items that can be simultaneously attended? J. Vis. 4:632. doi: $10.1167 / 4.8 .632$

Green, C. S., and Bavelier, D. (2006b). Effect of action video games on the spatial distribution of visuospatial attention. J. Exp. Psychol. Hum. Percept. Perform. 32:1465. doi: 10.1037/00961523.32.6.1465

Green, C. S., and Bavelier, D. (2007). Action-videogame experience alters the spatial resolution of vision. Psychol. Sci. 18, 88-94. doi: 10.1111/j.14679280.2007.01853.x

Green, C. S., and Bavelier, D. (2008). Exercising your brain: a review of human brain plasticity and training-induced learning. Psychol. Aging 23, 692-701. doi: 10.1037/a0014345
Greitemeyer, T., and Osswald, S. (2010). Effects of prosocial video games on prosocial behavior. J. Pers. Soc. Psychol. 98, 211-221. doi: 10.1037/a0016997

Hamlen, K. R. (2013). Understanding children's choices and cognition in video game play: a synthesis of three studies. Z. Psychol. 221, 107-114. doi: 10.1027/2151-2604/a000136

Harlow, H. F. (1949). The formation of learning sets. Psychol. Rev. 56, 51-65. doi: 10.1037/h00 62474

Hubert-Wallander, B., Green, C. S., Sugarman, M., and Bavelier, D. (2011). Changes in search rate but not in the dynamics of exogenous attention in action videogame players. Atten. Percept. Psychophys. 73, 2399-2412. doi: 10.3758/s13414011-0194-7

Hwang, G.-J., and Wu, P.-H. (2012). Advancements and trends in digital game-based learning research: a review of publications in selected journals from 2001 to 2010. Br. J. Educ. Technol. 43, E6-E10. doi: 10.1111/j.1467-8535.2011.01242.x

Jang, Y., and Ryu, S. (2011). Exploring game experiences and game leadership in massively multiplayer online role-playing games. $\mathrm{Br}$. J Educ. Technol. 42, 616-623. doi: 10.1111/j.14678535.2010.01064.x

Jenkins, H. (2005). Reality Bytes: Eight Myths About Video Games Debunked (Essay). PBS. Available online at: http://www.pbs.org/kcts/ videogamerevolution/impact/myths.html

Karle, B. A., and James, W. (2011). The impact of action video game play on attention and cognitive control. Available online at: http://digital commons.mcmaster.ca/opendissertations/6129/

Knight, R. T., Richard Staines, W., Swick, D., and Chao, L. L. (1999). Prefrontal cortex regulates inhibition and excitation in distributed neural networks. Acta Psychologica, 101, 159-178. doi: 10.1016/S0001-6918(99)00004-9

Kondo, H., Osaka, N., and Osaka, M. (2004). Cooperation of the anterior cingulate cortex and dorsolateral prefrontal cortex for attention shifting. Neuroimage 23, 670-679. doi: 10.1016/j.neuroimage.2004.06.014

Krishnan, L., Kang, A., Sperling, G., and Srinivasan, R. (2013). Neural strategies for selective attention distinguish fast-action video game players. Brain Topogr. 26, 83-97. doi: 10.1007/s10548-0120232-3

Kristjánsson, Á. (2013). The case for causal influences of action videogame play upon vision and attention. Atten. Percept. Psychophys. 75, 667-672. doi: 10.3758/s13414-013-0427-Z

Kühn, S., Gleich, T., Lorenz, R. C., Lindenberger, U., and Gallinat, J. (2014). Playing Super Mario induces structural brain plasticity: gray matter changes resulting from training with a commercial video game. Mol. Psychiatry 19, 265-271. doi: $10.1038 / \mathrm{mp} .2013 .120$

Latham, A. J., Patston, L. L. M., and Tippett, L. J. (2013). Just how expert are "expert" videogame players? Assessing the experience and expertise of video-game players across "action" video-game genres. Front. Psychol. 4:941. doi: 10.3389/fpsyg.2013.00941

Lenhart, A., Kahne, J., Middaugh, E., MacGill, A. R., Evans, C., and Vitak, J. (2008). Teens, Video Games, and Civics: Teens' Gaming Experiences Are Diverse 
and Include Significant Social Interaction and Civic Engagement. Washington, DC: Pew Internet \& American Life Project.

Levy, R., and Goldman-Rakic, P. S. (2000). "Segregation of working memory functions within the dorsolateral prefrontal cortex," in Executive Control and the Frontal Lobe: Current Issues, eds W. X. Schneider, A. M. Owen, and J. Duncan (Springer Berlin Heidelberg), 23-32. Available online at: http:// link.springer.com/chapter/10.1007/978-3-642-597 94-7_4

Lewis, J. M., Trinh, P., and Kirsh, D. (2011). "A corpus analysis of strategy video game play in starcraft: brood war," in Proceedings of the 33rd Annual Conference of the Cognitive Science Society 687692. Available online at: http://mindmodeling.org/ cogsci2011/papers/0138/paper0138.pdf

MacDonald, A. W., Cohen, J. D., Stenger, V. A., and Carter, C. S. (2000). Dissociating the role of the dorsolateral prefrontal and anterior cingulate cortex in cognitive control. Science 288, 1835-1838. doi: 10.1126/science.288.5472.1835

Maclin, E. L., Mathewson, K. E., Low, K. A., Boot, W. R., Kramer, A. F., Fabiani, M., et al. (2011). Learning to multitask: effects of video game practice on electrophysiological indices of attention and resource allocation. Psychophysiology 48, 1173-1183. doi: 10.1111/j.1469-8986.2011. 01189.x

Mathewson, K. E., Basak, C., Maclin, E. L., Low, K. A., Boot, W. R., Kramer, A. F., et al. (2012). Different slopes for different folks: alpha and delta EEG power predict subsequent video game learning rate and improvements in cognitive control tasks. Psychophysiology 49, 1558-1570. doi: 10.1111/j.1469-8986.2012.01474.x

Mishra, J., Zinni, M., Bavelier, D., and Hillyard, S. A. (2011). Neural basis of superior performance of action videogame players in an attentiondemanding task. J. Neurosci. 31, 992-998. doi: 10.1523/JNEUROSCI.4834-10.2011

Nagahama, Y., Okada, T., Katsumi, Y., Hayashi, T., Yamauchi, H., Oyanagi, C., et al. (2001). Dissociable mechanisms of attentional control within the human prefrontal cortex. Cereb. Cortex 11, 85-92. doi: 10.1093/cercor/11.1.85

Petrides, M. (2000). "The role of the middorsolateral prefrontal cortex in working memory," in Executive Control and the Frontal Lobe: Current Issues, eds W. X. Schneider, A. M. Owen, and J. Duncan (Springer Berlin Heidelberg), 44-54. Available online at: http:// link.springer.com/chapter/10.1007/978-3-642-597 94-7_6
Pivec, M. (2007). Editorial: play and learn: potentials of game-based learning. Br. J. Educ. Technol. 38, 387-393. doi: 10.1111/j.1467-8535.2007.00722.x

Poling, N. D. (2013). Collaboration, Teamwork, and Team Cohesion in a Starcraft 2 Digital Game-Based Course. University Of Florida. Available online at: http://gradworks.umi.com/35/86/3586632.html

Prensky, M. (2003). Digital game-based learning. Comput. Entertain. 1, 21-21. doi: 10.1145/950566. 950596

Prensky, M. (2005). Computer games and learning: digital game-based learning. Handb. Comput. Game Stud. 18, 97-122.

Przybylski, A. K. (2014). Electronic gaming and psychosocial adjustment. Pediatrics 134, e716-e722. doi: 10.1542/peds.2013-4021

Ridderinkhof, K. R., van den Wildenberg, W. P. M., Segalowitz, S. J., and Carter, C. S. (2004). Neurocognitive mechanisms of cognitive control: the role of prefrontal cortex in action selection, response inhibition, performance monitoring, and reward-based learning. Brain Cogn. 56, 129-140. doi: 10.1016/j.bandc.2004.09.016

Rowell, L. (2010). Nailing the coffin shut on doubts that violent video games stimulate aggression: comment on Anderson et al. (2010). Psychol. Bull. 136, 179-181. doi: 10.1037/a0018567

Schubert, T., and Strobach, T. (2012). Video game experience and optimized executive control skills-on false positives and false negatives: reply to Boot and Simons (2012). Acta Psychol. 141, 278-280. doi: 10.1016/j.actpsy.2012.06.010

Squire, K. (2005). Changing the game: what happens when video games enter the classroom? Innovate. J. Online Educ. 1.

Stansbury, J. A., and Munro, G. D. (2013). Gaming in the classroom an innovative way to teach factorial designs. Teach. Psychol. 40, 148-152. doi: 10.1177/0098628312475037

Stansbury, J. A., Wheeler, E. A., and Buckingham, J. T. (2014). Can Wii engage college-level learners? use of commercial off-the-shelf gaming in an introductory statistics course. Comput. Schools 31, 103-115. doi: 10.1080/07380569.2014.879791

Strobach, T., Frensch, P. A., and Schubert, T. (2012). Video game practice optimizes executive control skills in dual-task and task switching situations. Acta Psychol. 140, 13-24. doi: 10.1016/j.actpsy.2012.02.001

Sungur, H., and Boduroglu, A. (2012). Action video game players form more detailed representation of objects. Acta Psychol. 139, 327-334. doi: 10.1016/j.actpsy.2011.12.002

Voss, M. W., Prakash, R. S., Erickson, K. I., Boot, W. R., Basak, C., Neider, M. B., et al. (2012). Effects of training strategies implemented in a complex videogame on functional connectivity of attentional networks. Neuroimage 59, 138-148. doi: 10.1016/j.neuroimage.2011.03.052

West, G. L., Stevens, S. A., Pun, C., and Pratt, J. (2008). Visuospatial experience modulates attentional capture: evidence from action video game players. J. Vis. 8, 13-13. doi: 10.1167/8.16.13

Wu, S., Cheng, C. K., Feng, J., D’Angelo, L., Alain, C., and Spence, I. (2012). Playing a firstperson shooter video game induces neuroplastic change. J. Cogn. Neurosci. 24, 1286-1293. doi: 10.1162/jocn_a_00192

$\mathrm{Wu}$, S., and Spence, I. (2013). Playing shooter and driving videogames improves top-down guidance in visual search. Atten. Percept. Psychophys. 75, 673-686. doi: 10.3758/s13414-013-0440-2

Yee, N. (2003). Learning Leadership Skills. Available online from "The Daedalus Project" at: http:// www.nickyee.com/daedalus/archives/000338.php

Yee, N. (2006). The demographics, motivations, and derived experiences of users of massively multiuser online graphical environments. Presence 15, 309-329. doi: 10.1162/pres.15.3.309

Young, M. F., Slota, S., Cutter, A. B., Jalette, G., Mullin, G., Lai, B., et al. (2012). Our princess is in another castle a review of trends in serious gaming for education. Rev. Educ. Res. 82, 61-89. doi: $10.3102 / 0034654312436980$

Zhong, Z.-J. (2011). The effects of collective MMORPG (Massively Multiplayer Online Role-Playing Games) play on gamers' online and offline social capital. Comput. Human Behav. 27, 2352-2363. doi: 10.1016/j.chb.2011.07.014

Conflict of Interest Statement: The author is a scientific consultant for a company that specializes in cognitive training video games.

Received: 15 July 2014; accepted: 12 September 2014; published online: 30 September 2014.

Citation: Ashinoff BK (2014) The potential of video games as a pedagogical tool. Front. Psychol. 5:1109. doi: 10.3389/fpsyg.2014.01109

This article was submitted to Educational Psychology, a section of the journal Frontiers in Psychology.

Copyright (c) 2014 Ashinoff. This is an open-access article distributed under the terms of the Creative Commons Attribution License (CC BY). The use, distribution or reproduction in other forums is permitted, provided the original author(s) or licensor are credited and that the original publication in this journal is cited, in accordance with accepted academic practice. No use, distribution or reproduction is permitted which does not comply with these terms. 